\title{
Aspectos histoquímicos e morfológicos de grãos de café de diferentes qualidades
}

\author{
Histological and morphological aspects of different grain coffee qualities \\ Patrícia de Fátima Pereira Goulart ${ }^{\mathrm{I}}$ José Donizeti Alves ${ }^{\mathrm{II}}$ Evaristo Mauro de Castro ${ }^{\mathrm{II}}$ \\ Daniela Deitos Fries ${ }^{\mathrm{II}}$ Marcelo Murad Magalhães" Hyrandir Cabral de Melo ${ }^{\mathrm{II}}$
}

\section{RESUMO}

Este trabalho teve por objetivo relacionar aspectos histoquímicos e morfológicos de grãos secos de café com a qualidade destes classificadas como bebida mole, dura e rio. Paralelamente a esses estudos, foram realizadas em cada lote de grãos a lixiviação de potássio, a condutividade elétrica e a atividade da polifenol oxidase. Uma maior lixiviação de potássio, com o conseqüente aumento na condutividade elétrica, mostrou ser um forte indicador de danos na membrana e parede celular. Este dano foi confirmado por fotomicrografias em estudos histoquímicos e morfológicos de grãos de café. Estes estudos mostraram que no café bebida mole havia corpos lipídicos globulares bem definidos no interior dos protoplastos. Com a perda da qualidade da bebida para dura e rio, verificouse que os lipídeos não mais se apresentaram em corpos lipídicos bem definidos, estavam localizados nas regiões periféricas do protoplasto e algumas vezes extravasados no tecido devido à degradação da parede celular.

Palavras-chave: morfologia, lipídeo, bebida, óleo.

\section{ABSTRACT}

This research studied the histological and morphological aspects of the dry grain coffee classified as 'mole, 'dura' and 'rio' beverage. Concomitantly to these studies there were realized in each group of grains, potassium lixiviation, electric conductivity and polyphenol oxidase activity. A higher potassium lixiviation with the consequent increase in electric conductivity showed to be a strong indicator of membrane and cell wall damage. This damage was confirmed by histological and morphological studies of coffee grains. These studies showed that coffee beverage 'mole' had well defined lipidic bodies in the interior of protoplasts. During the beverage quality loss to 'dura' and 'rio', it was observed that lipids did not appear in well defined lipidic bodies like 'mole' coffee beverage, were localized in periphery of the protoplasts and sometimes extravased into the tissue due the degradation in cell wall.

Key words: morphology, lipids, flavor, oil.

\section{INTRODUÇÃO}

São poucos os trabalhos que abordam a morfologia e a anatomia do grão de café. O trabalho anatômico pioneiro realizado por DEDECCA (1957) mostra que o fruto cereja é constituído de casca ou exocarpo, mesocarpo, contendo a polpa e mucilagem e o grão, recoberto pelo pergaminho.

Por ser o endosperma a parte mais importante do grão, do ponto de vista econômico e fisiológico, tem sido objeto de estudos no que diz respeito a sua composição química. Segundo DEDECCA (1957), ele encerra, além de água, proteínas, alcalóides, óleos, açúcares dextrina, pentosanas, celulose, ácidos derivados da cafeína e outros ácidos. As reservas de lipídeos, de uma maneira geral, podem ser facilmente visualizadas como numerosas gotas esféricas no interior das células, quando estas estão ainda preservadas.

A partir da constatação de que o manejo inadequado dos frutos de café nas fases pré e póscolheita levam à degeneração das membranas e da parede celular (SALAZAR et al., 1994), com a subseqüente perda do controle da permeabilidade e a deterioração mais rápida do grão, objetivou-se estudar, neste trabalho, a relação entre aspectos histoquímicos e morfológicos de grãos secos de café com a qualidade dos mesmos, classificados como bebida mole, dura e rio.

\section{MATERIAL E MÉTODOS}

Para análises histoquímicas e morfológicas foram utilizadas amostras compostas por grãos secos

\footnotetext{
'Departamento de Nutrição/Fisiologia Pós-colheita, Centro Universitário de Lavras (UNILAVRAS/FACISA), Lavras, MG, Brasil. "Departamento de Biologia/Setor Fisiologia Vegetal, Universidade Federal de Lavras (UFLA), CP 3037, 37200-000, Lavras, MG, Brasil. E-mail: emcastro@ufla.br. *Autor para correspondência.
} 
de cafés classificados como de bebida mole, dura e rio, pela Cooperativa de São Sebastião do Paraíso - MG. As amostras de grãos foram submersas em água destilada por quatro dias e mantidas sob temperatura ambiente. As secções destinadas às reações histoquímicas, obtidas mediante corte à mão livre com o auxílio de uma lâmina de barbear, foram tratadas durante três minutos com o reagente Sudan IV em solução etanólica a $80 \%$ para a visualização de lipídeos, segundo o protocolo proposto por JENSEN (1962) com modificações.

O estudo morfológico da parede celular foi realizado em dez grãos secos para cada tipo de bebida, fixados por 72 horas em FAA70 ( $5 \mathrm{~mL}$ de formaldeido, $5 \mathrm{~mL}$ de ácido acético e $90 \mathrm{~mL}$ de álcool etílico). Para o preparo das lâminas permanentes dos cortes, utilizouse a técnica de inclusão em parafina após desidratação em série alcoólica etílica, segundo JOHANSEN (1940).

Os grãos emblocados em parafina foram cortados transversalmente com o auxílio de um micrótomo rotatório e submetidos ao processo de dupla coloração com safranina e azul de astra na proporção de 7:3, segundo recomendação de KRAUS \& ARDUIN (1997).

As fotomicrografias foram feitas com o auxílio de um fotomicroscópio Olympus BX-60 acoplado a uma ocular micrométrica.

Para lixiviação de potássio, condutividade elétrica e atividade da polifenol oxidase, foram analisadas amostras de grãos de cada tipo de bebida, em três repetições. Inicialmente foi determinada a condutividade elétrica utilizando-se a metodologia proposta por LOEFFLER et al. (1988), com pequenas modificações. Para tanto, foram colocadas três amostras (sem escolha dos grãos defeituosos) de 50 grãos de cada parcela, em copos plásticos de $180 \mathrm{~mL}$, contendo $75 \mathrm{~mL}$ de água deionizada. A seguir, esses recipientes foram colocados em estufa ventilada, a $25^{\circ} \mathrm{C}$, por 5 horas, procedendo-se à leitura da condutividade elétrica da solução, a cada 30 minutos, em aparelho DIGIMED CD20.

Imediatamente após a leitura da condutividade elétrica, procedeu-se a quantificação do potássio lixiviado utilizando-se o fotômetro de chama DIGIMED NK-2002. Amostras de 50g de grãos de café imersas em $500 \mathrm{~mL}$ de água destilada, à temperatura ambiente, originaram alíquotas que foram removidas em diferentes intervalos de tempo (30 minutos) para a determinação do potássio lixiviado. A quantidade de potássio lixiviado foi quantificada segundo metodologia proposta por PRETE (1992), expressandose o resultado em $\mathrm{ppm} / \mathrm{g}$ de amostra.
A obtenção de extrato para a atividade da polifenoloxidase foi feita, segundo a metodologia proposta por MAZZAFERA \& ROBINSON (2000). O meio de extração foi composto de tampão fosfato de sódio $0,1 \mathrm{M}, \mathrm{pH} 7,0$, contendo $2 \%$ de ácido ascórbico e $20 \%$ de polivinilpirrolidona (PVPP) (peso/peso). Após agitação por 20 minutos, o extrato foi centrifugado a $36.000 \mathrm{~g}$ por 20 minutos, e o sobrenadante eluído em mini colunas cromatográficas do tipo exclusão molecular, PD-10 Sephadex G-25, com o objetivo de se eliminar possíveis resíduos de ácido ascórbico e do PVPP. A eliminação do ácido ascórbico é uma etapa importante, uma vez que o mesmo, quando presente no extrato, pode complexar-se com a polifenol oxidase, inibindo sua atividade. Todas estas etapas foram conduzidas a $4^{\circ} \mathrm{C}$, de acordo com CHEVALIER et al. (1999). Para a dosagem da atividade da polifenol oxidase, tomando-se por base o consumo de oxigênio, utilizou-se a metodologia descrita por MAZZAFERA et al. (2002). Para tanto, tomaram-se 850(L de tampão fosfato $0,025 \mathrm{M}$, a pH 6,0 , onde foram adicionados $140 \mu \mathrm{L}$ do extrato e $50 \mu \mathrm{L}$ de ácido clorogênico $20 \mathrm{mM}$ para a obtenção de uma concentração final de $1 \mathrm{mM}$. A medida do consumo de $\mathrm{O}_{2}$ foi realizada no equipamento Respire 1 da Hansatech, UK, durante 180 segundos, sendo utilizados, para o cálculo da atividade, os primeiros 120 segundos de reação.

\section{RESULTADOS E DISCUSSÃO}

Os resultados do teste histoquímico das secções tratadas com o reagente Sudan IV mostraram a presença de lipídeos nas células parenquimatosas do endosperma dos grãos correspondentes aos três tipos de bebidas (Figura 1). Observa-se, entretanto, que, no café bebida mole, os corpos lipídicos se apresentam de forma globular, tal como verifica-se no detalhe no interior dos protoplastos (Figura 1B). Este tecido, por sua vez, encontra-se direta e uniformemente revestido por um envoltório seminal, descrito por DEDECCA (1957) como película prateada ou espermoderma, que é constituído por numerosas células esclerenquimatosas com parede celular secundária. Neste café de melhor qualidade, a película prateada se apresenta fortemente aderida na parede periclinal externa das células endospérmicas.

Para cafés de melhor qualidade de bebida, a presença dos lipídeos nas bordas dos grãos funcionam, na torrefação, como peneira seletiva, retendo os compostos aromáticos que são formados pela pirólise durante o aquecimento (AMORIM, 1978; CARVALHO et al.,1997). Desse modo, a preservação dos lipídeos nessa forma no café bebida mole, provavelmente, deve- 


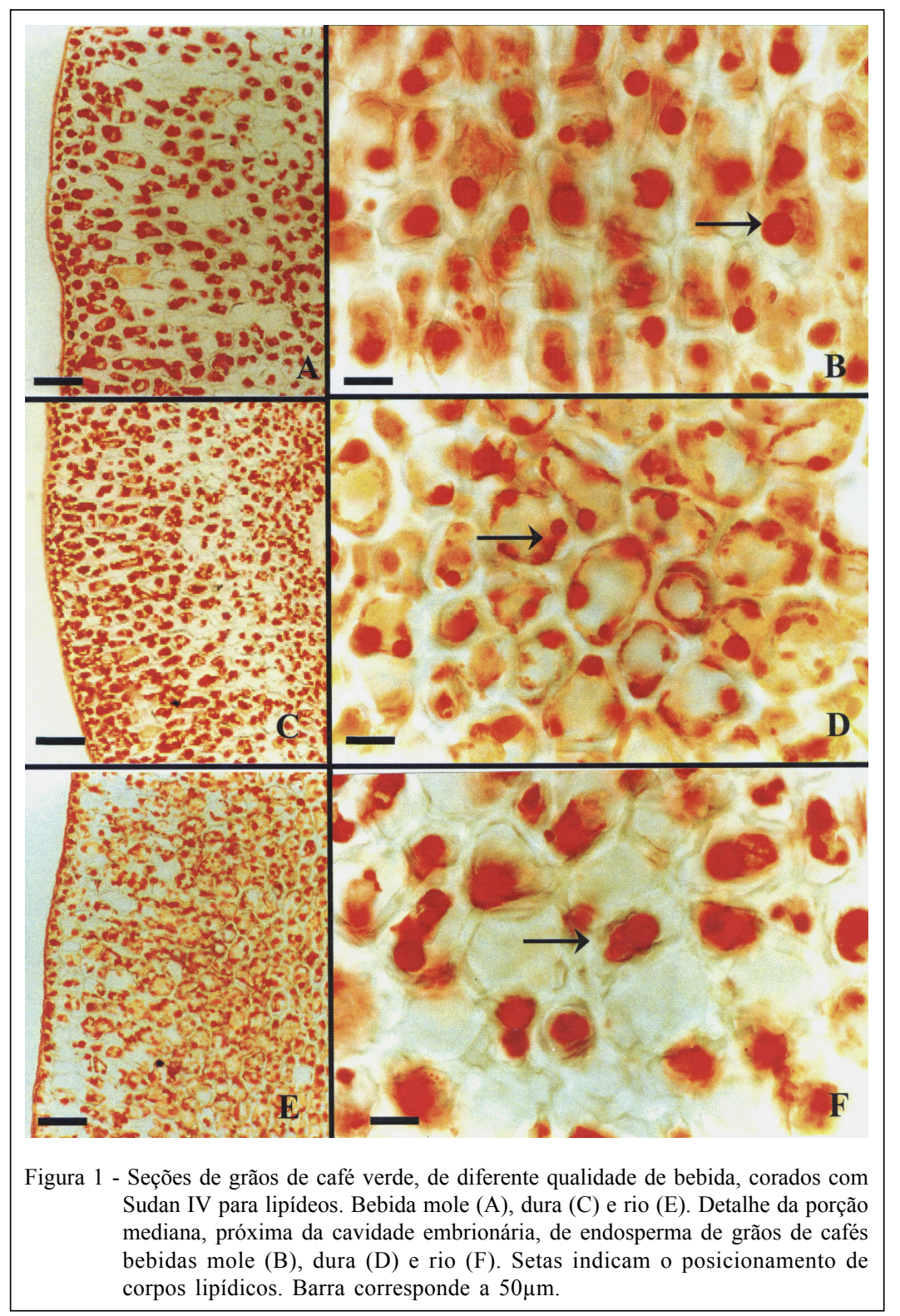

se à integridade da parede celular, a qual pode ser observada na figura $2 \mathrm{~A}$.

Observou-se que os lipídeos apresentaramse, homogeneamente, distribuídos no tecido endospérmico dos grãos do café bebida dura (Figura 1C) e rio (Figura 1E). Nestes tipos de cafés, verifica-se que os lipídeos não mais se apresentam em corpos lipídicos centralizados e bem definidos na célula, como no café bebida mole (Figura 1B), mas dispersos e ocorrendo em regiões mais próximas à parede celular, em cafés bebida dura (Figura 1D) e rio (Figura 1F). Este derrame é resultado da degradação da parede celular, que se apresenta cada vez mais intensa, tendo como conseqüência a redução da qualidade da bebida (Figura 2D e 2F). Nos cafés de bebida dura, observam-se várias células, tanto na parte mais externa (Figura 2C), quanto na mais interna do endosperma (Figura 2D). Próximo ao embrião, há uma depressão da parede primária em vários pontos da parede celular. Provavelmente, a degradação da parede celular primária criou uma zona de menor resistência, devido à pressão celular, e assim ocorreu o deslocamento dos corpos lipídicos para os bordos das células, como observado na figura $1 \mathrm{D}$.

Com a perda da qualidade da bebida passando de dura para rio, verifica-se o desaparecimento da lamela média em algumas regiões

Ciência Rural, v.37, n.3, mai-jun, 2007. 


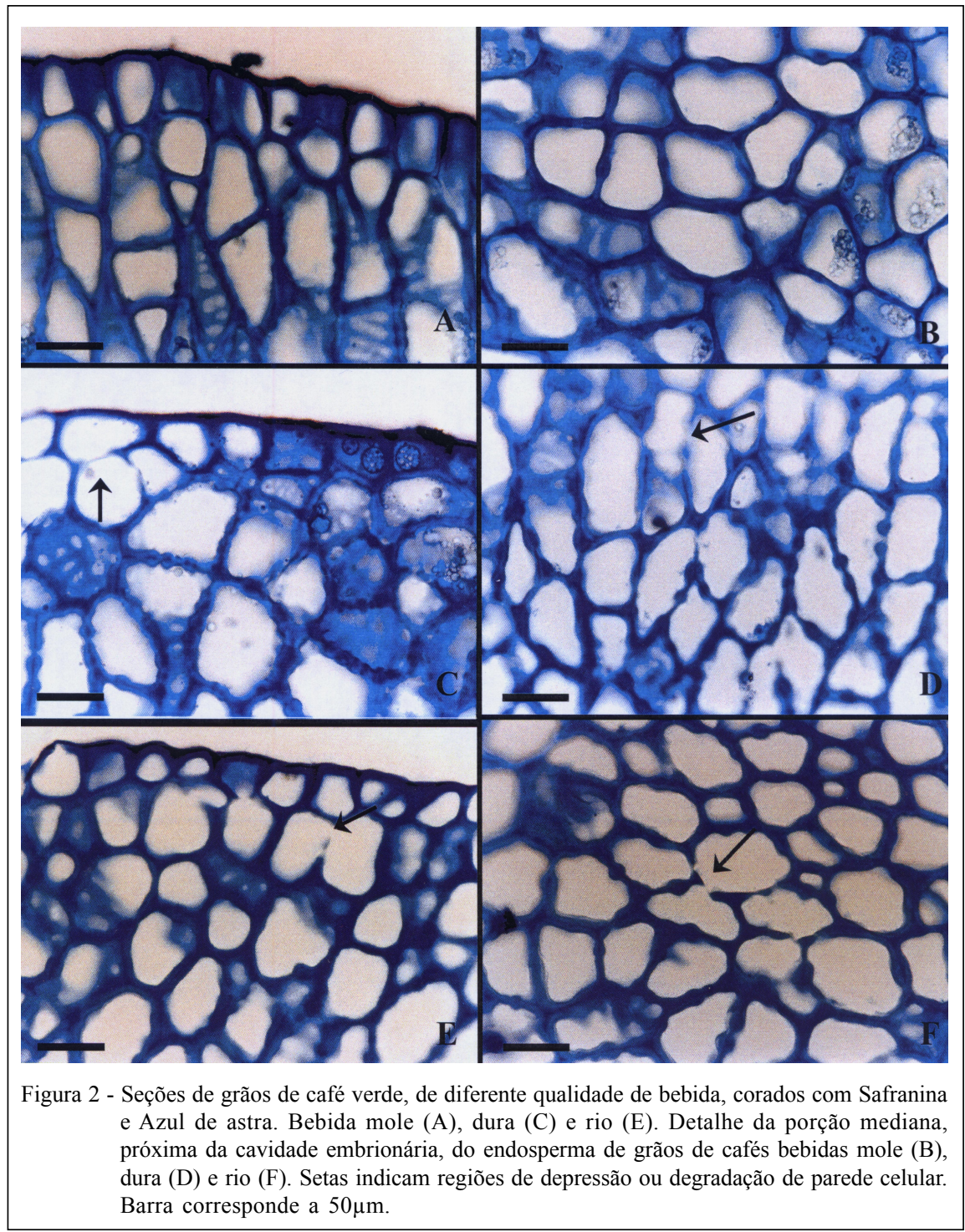

da parede celular, tanto na região periférica (Figura 2E), como na mais interna do endosperma (Figura 2F), o que possibilita um extravasamento de lipídeos para o apoplasto do tecido.

A degradação da parede celular que foi observada nos grãos de bebida dura (Figura 2C e 2D) e rio (Figura $2 \mathrm{E}$ e $2 \mathrm{~F}$ ) pode ser relacionada positivamente com os valores de condutividade elétrica que foram de 136,03 para bebida mole; 137,98 para dura e 195,23 u S $\mathrm{g}^{-1}$ para rio, também podendo ser relacionada com a lixiviação de potássio, cujos valores foram de 48,80 para a bebida mole, 51,58 para a dura e $72,16 \mathrm{ppm} \mathrm{g}^{-1}$ para rio. A maior lixiviação de potássio e o aumento da condutividade elétrica nos cafés de menores qualidades indicam, provavelmente, que as membranas e paredes celulares sejam as responsáveis diretas e indiretamente pelas transformações no grão, quando este se deteriora.

Estes resultados comprovam que cafés de menor qualidade apresentam células desestruturadas, onde os diferentes graus de degradação celular descaracterizam o tecido endospérmico pela desorganização dos corpos lipídicos dentro das células, ocasionando reações que culminam num processo de deterioração da qualidade da bebida. Neste aspecto, AMORIM (1978) e PIMENTA (2004) sugerem que o extravasamento dos lipídeos para todo o endosperma possa provocar alterações qualitativas e quantitativas na sua composição, levantando a hipótese de que essas transformações sejam a causa principal da mudança de qualidade da bebida. Para esses autores, os lipídeos do grão de café atuam durante a torração 
como peneira seletiva, isto é, parte dos compostos aromáticos formados pela pirólise durante o aquecimento fica retida nesses óleos, enquanto outra é liberada.

Desse modo, a maior concentração de lipídeos nos bordos externos dos grãos de cafés de melhor qualidade favorece uma maior retenção do aroma, melhorando assim a qualidade do produto (AMORIM, 1978; AGUIAR et. al., 2005).

Observou-se um acréscimo proporcional entre a condutividade elétrica e a lixiviação de potássio com a perda da qualidade da bebida do café, apenas quando esta foi classificada pela prova de xícara. Estes resultados, somados com as observações anatômicas do grão, comprovam que a atividade da polifenol oxidase pode ser usada somente como um indicador da perda da qualidade da bebida do café, conforme proposto por AMORIM (1978) e CLIFFORD (1985).

\section{CONCLUSÕES}

Uma maior lixiviação de potássio, com o conseqüente aumento na condutividade elétrica, é um forte indicador de danos na membrana e na parede celular.

O café de bebida mole apresenta uma maior concentração de lipídeos na região periférica do grão, que se apresentaram como corpos lipídicos globulares bem definidos no interior dos protoplastos. Com a perda da qualidade da bebida, os lipídeos se apresentam homogeneamente distribuídos no tecido nos grãos do café bebida dura e rio. Nestes tipos de cafés, os lipídeos não mais se apresentam em corpos lipídicos bem definidos, como no café bebida mole, mas sim dispersos de forma irregular dentro da célula e nos espaços intercelulares.

\section{REFERÊNCIAS}

AGUIAR, A.T.E. et al. Variação no teor de lipídios em grãos de variedades de Coffea canephora. Pesquisa Agropecuária Brasileira, v.40, n.12, p.1251-1254, 2005.
AMORIM, H.V. Aspectos bioquímicos e histoquímicos do grão do café verde relacionados com a deterioração de qualidade. 1978. 85f. Tese (Livre-docência) - Escola Superior de Agricultura Luiz de Queiroz/USP, Piracicaba.

CARVALHO, V.D. et al. Fatores que afetam a qualidade do café. EPAMIG - Informe Agropecuário, v.18, n.187, p.520, 1997.

CHEVALIER, T. et al. Molecular cloning and characterization of apricot fruit polyphenoloxidase. Plant Physiology, v.119, p.1261-1270, 1999.

CLIFFORD, M. Chlorogenic acids. In: CLARKE, R.J.; MACRAE, R. (Eds). Coffee. London: Chemistry, Elsevier Science, 1985. V.1, p.153-202.

DEDECCA, D.M. Anatomia e desenvolvimento ontogenético de Coffea arábica L. var. Typica Cramer. Bragantia, v.16, p.315-355, 1957.

JENSEN, W.A. Botanical histochesmistry. San Francisco: Freeman, 1962. 408p.

JOHANSEN, D.A. Plant microtechnique. New York: Mc Graw-Hill, 1940. 528p.

KRAUS, J.; ARDUIM, E. Manual básico de métodos em morfologia vegetal. Seropédica: Edur, 1997. 198p.

LOEFFLER, T.M. et al. The bulk conductivity test as an indicator of soybean quality. Journal of Seed Technology, v.12, n.1, p.37-53, 1988.

MAZZAFERA, P. et al. Extração e dosagem da dosagem da atividade da polifenoloxidase do café. Scientia Agrícola, v.59, n.4, p.695-700, 2002.

MAZZAFERA, P.; ROBINSON, S.P. Characterization of polyphenoloxidase in coffee. Phytochemistry, v.55, p.285296,2000 .

PIMENTA, C.J. Qualidade do café. Lavras: UFLA, 2004. 304 p.

PRETE, C.E.C. Condutividade elétrica do exsudato de grãos de café (Coffea arabica $L$.) e sua relação com a qualidade da bebida. 1992. 125f. Tese (Doutorado em Fitotecnia) - Escola Superior de Agricultura Luiz de Queiroz/ USP, Piracicaba.

SALAZAR, G.M.R. et al. Estudio morfológico, anatomico y ultraestrutural del fruto de café Coffea arabica L. Cenicafé, v.45, n.3, p.93-105, 1994. 